\title{
How to relate the standing tree shape to internal wood characteristics: Proposal of an experimental method applied to poplar trees
}

\author{
Thiéry Constant*, Frédéric Mothe, Miguel Angel Badia and Laurent Saint-AndRe \\ LERFOB, UMR INRA-ENGREF, Wood Quality Research Team, Research Centre of Nancy, 54280 Champenoux, France
}

(Received 4 January 2002; accepted 8 July 2002)

\begin{abstract}
This paper presents an experimental method allowing 3D measurements of the geometry of a standing mature tree to be closely linked to the spatial distribution of internal wood properties. The accuracy of the geometrical information is assessed from repeated measurements performed on 10 mature poplar trees and demonstrates that wind is the most limiting factor. Since the method was developed to study the spatial distribution of tension wood, some pictures of the latter are presented. Furthermore, some preliminary relationships between variables derived from measurements such as the height, the local tree slope, the eccentricity of the tension wood area, or the eccentricity of the disc are discussed to illustrate the potential of the method.
\end{abstract}

standing tree / 3D digitising / internal structure / reaction wood / metrology

Résumé - Comment connecter la forme d'un arbre sur pied aux propriétés internes du bois : proposition d'une méthode expérimentale appliquée sur des peupliers. Cet article présente une méthode expérimentale de mesure de la géométrie tridimensionnelle d'un arbre sur pied mature permettant un couplage étroit avec la mesure des propriétés internes du bois. La précision de l'information géométrique est estimée à partir de mesures répétées sur 10 peupliers et met en évidence le vent comme principal facteur limitant. La méthode ayant été développée pour étudier la distribution spatiale du bois de tension, quelques illustrations de cette dernière sont présentées. En outre, des relations préliminaires liant des variables telles que la hauteur, l'inclinaison locale de l'arbre, l'excentricité de la zone de bois de tension ou l'excentricité de la rondelle sont discutées afin d'illustrer le potentiel de la méthode.

arbre sur pied / digitalisation 3D / structure interne / bois de réaction / métrologie

\section{INTRODUCTION}

For technological purposes, the quality of wood products is dramatically decreased by the amount of reaction wood. The internal quality of a tree depends on numerous impacts occurring throughout its life and tree shape is the visible result of past growth. The forester uses this criterion when he selects trees for thinning. At a less obvious level, the occurrence of reaction wood is linked to the history of tree growth, and in particular to the evolution of its shape where the environmental factors and the competition for light play an important role.

During each growth cycle, the cambium produces new cells. After maturation, they contribute with more or less intensity to growth stresses. The level of stress is increased in the case of reaction wood and is the driving force to tree shape change [2, $5-7,10]$. This phenomenon is often accompanied, but not systematically $[3,9,12,16]$, by anisotropic growth in diameter which creates eccentricity for instance.

Thus, at a given moment, the relationship between the 3D geometry of the annual growth rings and the occurrence of reaction wood reflects the history of past secondary growth and of past tree shape to a certain extent. The geometrical information describing the shape, and the 3D spatial location of the different entities that constitute a tree falls into the domain of plant architecture. Godin [8] reviewed in detail the different methods for representing and coding this type of information. Most of the references deal with the aerial or underground components $[4,14]$ in order to study their structures and to appreciate important functions such as the mechanisms of competition.

Several scientific works have already been devoted to the relationship between tree shape and internal wood characterisation especially when looking at the relevance and spatial distribution of reaction wood in mature trees. Radi and Castera [11] studied two maritime pines by measuring the shape along an average line of the trunk and by cutting one disc at each whorl. The percentage of compression wood and the eccentricity, defined as the ratio of the maximum radius to the opposite one, were related to the height up to 6 metres. Beyond this height the relationships became less obvious and the relationship with 
local inclination was poor. They pinpointed the relationship between the percentage of compression wood and events such as tilting or the first thinning. More recently Alteyrac et al. [1] also analysed maritime pine tree and successfully compared its shape to computerised simulations of the tree shape and internal characteristics. They measured several basic wood properties (modulus of elasticity, basic density, moisture content), the tree architecture and stem dimension as well as residual growth stresses which were used for further modelling. The shape measurement was based on the measurement of targets attached to the trunk and located by a triangulation method from three fixed posts. Thomas [15] developed a quick photogrammetric method to characterise trunk shape up to 8 meters height in a study which linked the trunk shape with the internal quality of Pinus sylvestris. They concluded that the current shape of a trunk is a good indicator of the location of compression wood but the relationship is complex and difficult to assess without any knowledge of the tree history. Furthermore Thomas confirmed, like several others, that the eccentricity of the stem is statistically linked with the occurrence of compression wood.

The objective of this paper is to present the method developed in our laboratory to measure the geometry of a standing mature tree and to relate it to the occurrence of reaction wood, even though that growth stresses also must be considered.

To comply with experimental constraints, the tree is usually divided into subsets, such as logs, discs and even smaller specimens. The objective of the proposed method was to obtain the geometry of these different objects in the coordinate system corresponding to the standing tree, in order to analyse the spatial distribution of wood characteristics using the most accurate data. Our main assumption was to consider the tree as a rigid body and to neglect the changes of shape of the stem and logs before and after felling and bucking. For that it was necessary to know the location of the considered object in a parent reference system before its characterisation in a morphologically more suitable coordinate system.

Here three reference levels were used: (i) the first one linked the field measurement and the standing tree where the measured points deliver a rough skeleton of the tree, (ii) the second one where the external shape of each log was measured in detail and (iii) the third one where the surface of each crosssection was measured.

This paper reports the results of measurements of ten poplar trees and the internal wood characteristics of one individual tree to illustrate the method and to assess its accuracy.

\section{MATERIALS AND METHODS}

\subsection{Plant material}

Ten poplar trees were used to test the method presented in this paper. Their characteristics are shown in Table I.

\subsection{Principle of the method}

In a three-dimensional (3D) space associated with a Cartesian coordinate system, the position of a rigid body was defined by 6 degrees of freedom corresponding to 3 translations and 3 rotations respectively, along and around each axis of the coordinate system. This position can be defined from 6 out of 9 coordinates of three nonaligned points of the rigid body. That was the basis of the method: by acquiring the coordinates of three non-aligned points on each object in two different coordinate systems, it was possible to deduce the mathematical transformation corresponding to the change between both coordinate systems.

In practice, nails defined the points, and the considered objects were the $\log$ in the tree or the disc in the log.

Once mathematically defined and applied to all measured objects, these transformations deliver the coordinates of each measured point in the coordinate system in which the standing tree was measured. These data could be used directly for visualisation purposes or transformed and exploited in data analyses.

\subsection{Field measurement}

\subsubsection{Target positioning}

On the standing tree, a minimum of three targets per log was defined by nails associated with a coloured plastic tag to make the reference point easy to recognize. The reference points were positioned in a way which allowed to divide the trunk into logs with lengths between $0.5 \mathrm{~m}$ and $2.0 \mathrm{~m}$, suitable for the following operations. In practice, the targets were placed at the top, at the bottom and in the middle of each log. As a result, six targets per log were used (Fig. 1). In order to position the targets, ladders or an aerial lift were used to reach about 15 meters height.

\subsubsection{Target measurements}

A tacheometer (Total Station LEICA TCR307 reflectorless) was used in order to acquire the 3D coordinates of each target set on the trunk.

In addition to the defined targets, extra points were measured on the main branches of the crown.

Then the tree was felled and bucked with respect to the planned log length, taking care to not damage the targets. For none of the 10 trees measured by this method, the targets have been damaged by felling, logging or transport operations.

\subsection{Laboratory measurements}

\subsubsection{Measurement of the external shape of a log}

Each log was fixed onto an apparatus called AMEB (Appareil de Mesure de l'Enveloppe des Billons) (Fig. 2) which was built in our laboratory and has certain similarities to a lathe. The log was maintained between a fixed headstock and a moving tailstock mounted on slides and moved by an endless screw in order to tighten the log longitudinally. Two rotating axes were integrated in their upper parts and defined by building a horizontal rotation axis for the log. The log was attached to these axes by screws through vertical plates. By means of a cog-wheel and an endless screw attached to the axis of the fixed headstock, the log could be rotated and maintained at a chosen angular position. An angular coder measured the latter.

Moreover, a laser distancemeter was mounted on a longitudinal 1 -axis robot ensuring that the sensor moved parallel to the rotation axis of the log. The technical characteristics of the main components are given in the Annex 1. By means of a personal computer and controlling devices, the longitudinal location of the laser device was controlled by fixed displacement $(1 \mathrm{~cm})$ between both ends of the log. After each longitudinal step, the radial distance measured by the sensor was 
Table I. Main dendrometric characteristics of the trees sampled with respect to shape indices i.e. straight, leaning and curved tree $(\mathrm{Ht}=$ total height, $\mathrm{DBH}=$ diameter at breast height).

\begin{tabular}{|c|c|c|c|c|c|c|c|c|}
\hline Name & Species & Region & Age (year) & $\mathrm{Ht}(\mathrm{m})$ & $\mathrm{DBH}(\mathrm{cm})$ & $\mathrm{Ht} / \mathrm{DBH}$ & Crown surface $\left(\mathrm{m}^{2}\right)$ & Shape index \\
\hline FV1 & Unknown & $\begin{array}{c}\text { Velaine s/s } \\
\text { Amance } \\
\text { France }\end{array}$ & 42 & 28.3 & 42 & 67.4 & 70.2 & \\
\hline SI1 & $\begin{array}{l}\text { Populus x euramericana } \\
\text { cv. I } 214\end{array}$ & $\begin{array}{l}\text { Valle del Cinca } \\
\text { Spain }\end{array}$ & 16 & 30.5 & 38 & 80.5 & 63.3 & \\
\hline SI2 & $\begin{array}{l}\text { Populus } x \text { euramericana } \\
\text { cv. I } 214\end{array}$ & $\begin{array}{l}\text { Valle del Cinca } \\
\text { Spain }\end{array}$ & 17 & 28.9 & 43 & 66.5 & 44.2 & \\
\hline $\mathrm{SI} 3$ & $\begin{array}{c}\text { Populus } x \text { euramericana } \\
\text { cv. I } 214\end{array}$ & $\begin{array}{l}\text { Valle del Cinca } \\
\text { Spain }\end{array}$ & 16 & 28.5 & 36 & 79.9 & 52.5 & \\
\hline SM1 & $\begin{array}{c}\text { Populus x euramericana } \\
\text { cv. MC }\end{array}$ & $\begin{array}{l}\text { Valle del Cinca } \\
\text { Spain }\end{array}$ & 16 & 35.9 & 41 & 87.1 & 58.8 & \\
\hline SM2 & $\begin{array}{c}\text { Populus x euramericana } \\
\text { cv. MC }\end{array}$ & $\begin{array}{l}\text { Valle del Cinca } \\
\text { Spain }\end{array}$ & 16 & 30.2 & 40 & 74.7 & 39.0 & \\
\hline SM3 & $\begin{array}{c}\text { Populus x euramericana } \\
\text { cv. MC }\end{array}$ & $\begin{array}{l}\text { Valle del Cinca } \\
\text { Spain }\end{array}$ & 16 & 29.4 & 39 & 74.8 & 41.7 & \\
\hline SL1 & $\begin{array}{c}\text { Populus x euramericana } \\
\text { cv. Luisa Avanzo }\end{array}$ & $\begin{array}{l}\text { Valle del Cinca } \\
\text { Spain }\end{array}$ & 16 & 30.2 & 43 & 69.8 & 62.8 & \\
\hline SL2 & $\begin{array}{l}\text { Populus x euramericana } \\
\text { cv. Luisa Avanzo }\end{array}$ & $\begin{array}{l}\text { Valle del Cinca } \\
\text { Spain }\end{array}$ & 16 & 29.7 & 38 & 77.1 & 74.9 & \\
\hline SL3 & $\begin{array}{c}\text { Populus x euramericana } \\
\text { cv. Luisa Avanzo }\end{array}$ & $\begin{array}{l}\text { Valle del Cinca } \\
\text { Spain }\end{array}$ & 16 & 27.4 & 41 & 65.7 & 70.7 & \\
\hline
\end{tabular}

recorded automatically. By repeating the previous phase for a set of angular positions, for instance 36 positions corresponding to an angular step of $10^{\circ}$, a discrete description of the external shape of the log was achieved. The corresponding triplets were given in a cylindrical coordinate system defined by the rotation axis of the device, and can be easily transformed in the Cartesian coordinates.

\subsubsection{Target measurements and disc positioning}

After the external shape was measured, the location of each target was measured by controlling the motion of the robot and the rotation of the $\log$ to set the laser spot manually. These measurements were added to the set of data describing the log. At this stage, new targets were added to define the position of the discs which were used for further analyses. Using the same principle as above, three non-aligned nails per disc were used.

\subsubsection{Disc characterisation}

The next stage was to cut discs taking care to include the 3 relevant targets. In the example given, and to illustrate the method, the characterisation of the disc included the annual ring limits, the outline of the bark, the external limit of the black heart, and the edges of tension wood areas. The method used to detect macroscopically the tension wood areas is based on visual assessment of natural colour, which is shiner than normal wood ${ }^{1}$.

By superimposing a transparent sheet, the different lines and the projection of the 3 targets were traced using different colours. Then, this sheet was scanned at $100 \mathrm{ppi}$, and the image file was analysed with the image analysis software Visilog ${ }^{\circledR}$ 5.3. The procedure mainly consisted of a discretisation in small areas defined by angular sectors centred on the pith and intersecting the annual ring limits. Here, 360 angular sectors and five year rings in radial direction were used. Each of the small ring sectors was then characterised by its location, its age, its area, and the percentage of its area corresponding to tension wood or black heart.

Furthermore, a 3D geometrical description of the disc was obtained by using the $2 \mathrm{D}$ coordinates of the targets in the image completed by a manual measurement of the distance between the plane containing the surface of the disc and each target.

\subsection{Spatial reorganisation of the data}

The geometrical transformation defining the change of the coordinate system can be calculated by selecting 3 targets on the log whose coordinates were known in the coordinate system corresponding to

\footnotetext{
${ }^{1}$ A separated paper will be devoted to experimental validation of this method in comparisons to microscopic measurements.
} 


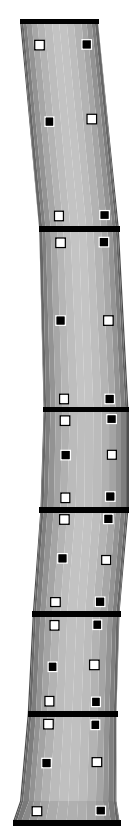

Figure 1. Tags positioning onto the living tree. Only 3 tags per log are required for the $3 \mathrm{D}$ reconstruction procedure. The supplemental tags are used to recover potential measurement errors.

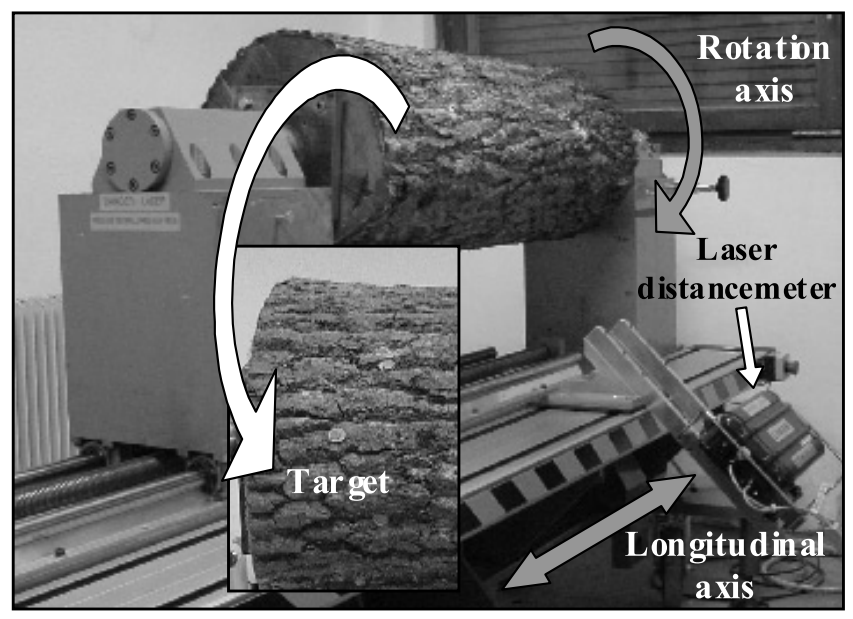

Figure 2. The AMEB device used to measure the external log shape and locate the targets set on the standing tree and the targets belonging to the discs.

the standing tree and in the second one related to the AMEB. The details are presented in Annex 2.

The transformation was applied to all points measured with AMEB including the targets of the discs. Using this transformation the coordinates of all points including the additional targets on the discs were inserted into the coordinate system in which the standing tree was measured.

The coordinates of the three targets of each disc were associated with their positions in the 3D coordinate system related to the image. The result was a precise location of the characteristics measured on each disc in the standing tree.

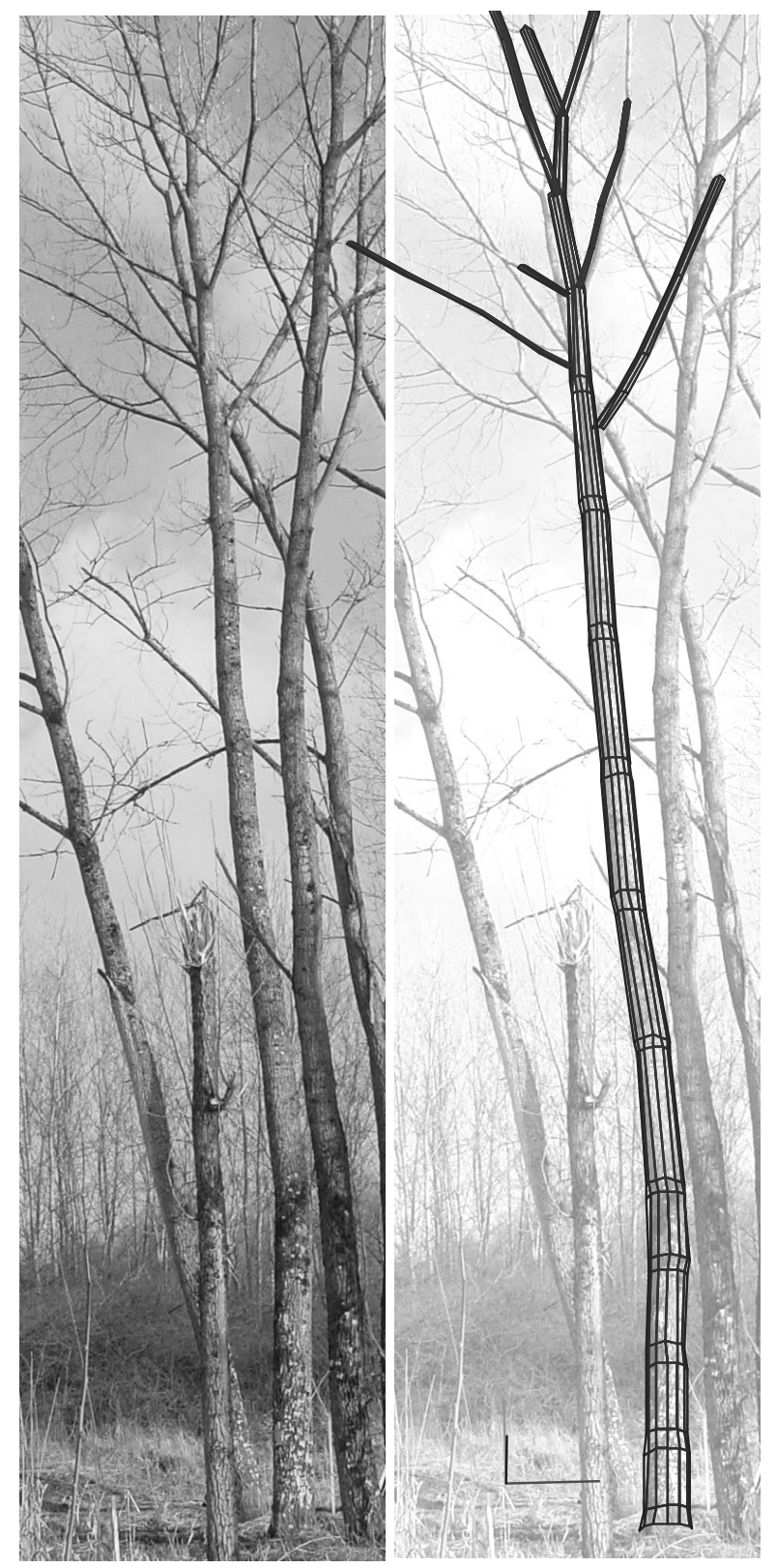

Figure 3. Photographic view of tree FV1 and 3D perspective view of the reconstructed shape.

\section{RESULTS AND DISCUSSION}

\subsection{Visualisation}

The comparison between the virtual model and a photograph was the initial qualitative approach of this method (Fig. 3). Data coherence may be verified at each stage of the reconstruction process using a visualisation software which allows to display and rotate each measured object (tree, logs, discs) rendered with polygonal facets (Fig. 4). 


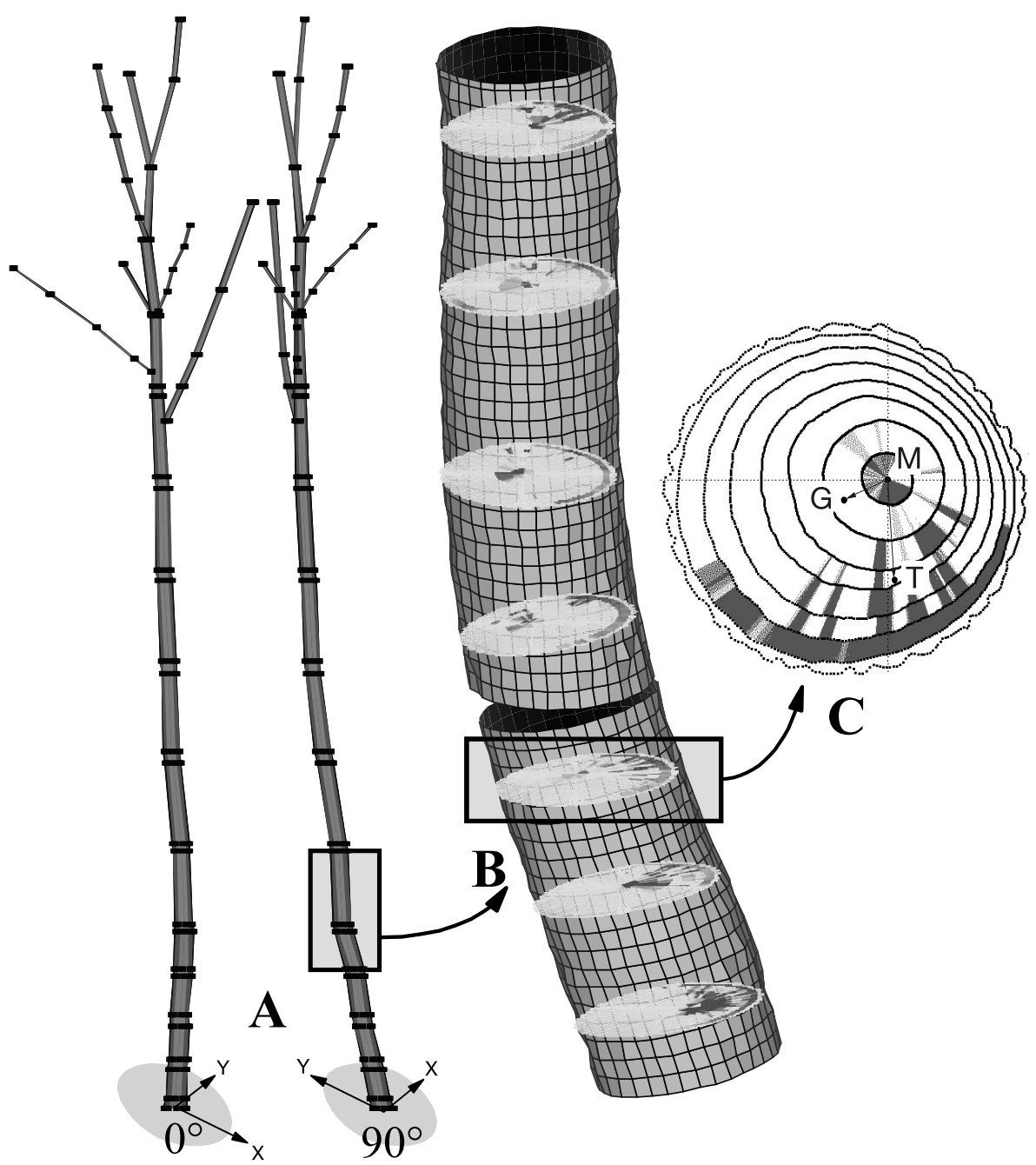

Figure 4. Illustration of the three levels of shape analysis for tree FV1: (A) skeleton of the standing tree; (B) reconstruction of the tree shape and of the sampled discs; (C) disc measurements of tension wood; location of the pith $(\mathrm{M})$, the disc centre of gravity $(\mathrm{G})$ and the centre of gravity of tension wood $(\mathrm{T})$.

\subsection{Precision}

Throughout the different stages of this method, the most critical point for accuracy of tree reconstruction is the measurement of the targets on the standing tree. An experiment was carried out to quantify the precision of an operator when targets were measured by means of the tacheometer. The targets were all measured twice without moving the total station in order to test the accuracy of the measurements. This experiment was performed for 9 different poplar trees selected for an on-going project and totalling 499 targets measured twice.

The results (Fig. 5) outline the wind effect since, for 3 out of 9 trees (SL1, SL2, SL3), a hampering wind was noticed in the field report, and in Figure 5a, the residual variance for the targets belonging to these trees is much higher than for the others. One notices that the residual variance for the $\mathrm{Z}$ axis was always low since $\mathrm{Z}$ corresponded to the vertical direction and consequently the effect of wind was mainly in the other directions.

Two more trees showed a relatively large residual variance for the axis Y, and this was probably due to the fact that the
Y-axis corresponded to the distance to the tree. This high level of variance can be linked to the principle of distance measurement which may depend on several uncontrolled external features.

A more detailed analysis of the residual variances for each axis with respect to the log height levels, coded from 1 (butt) to 10 (top) is shown in Figure 5b. The effect of wind was confirmed by the highest levels of variance since the log number 6 which corresponded to a height between 10 and $12 \mathrm{~m}$. Therefore, two different levels of variance can be considered to correspond respectively to measurements carried out under good conditions (bottom of the tree, no wind, no leaves), and under less favourable conditions (top of the tree, wind, leaves). The analysis of the residual variance are presented in Table II by distinguishing between two classes of accuracy for the target position: up to and including the sixth log, and above. In absence of a true reference method, those results will be used to estimate the accuracy of the method.

However, the second possibility to test the accuracy of the tacheometer measurements is the comparison of the distance between pairs of targets on the same log, which are measured 


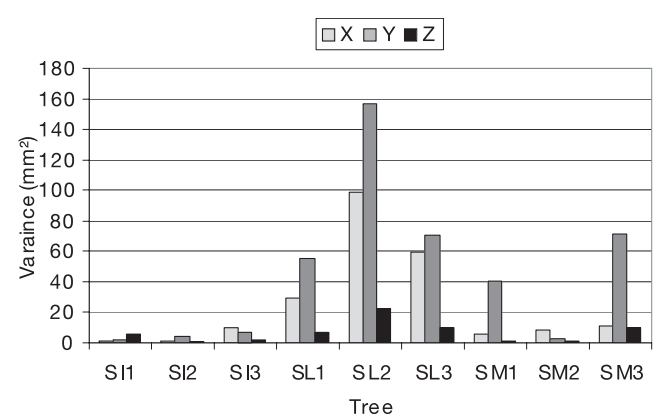

A

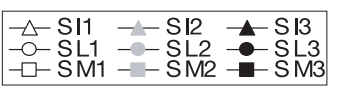

$x$
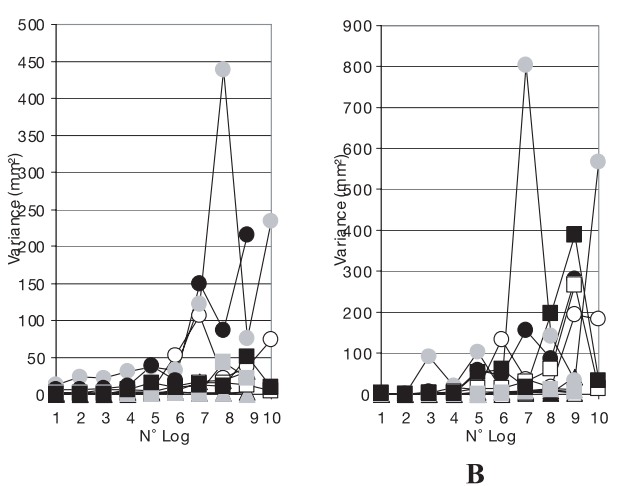

B
Figure 5. Variance of the difference of the coordinate for each axis X, Y, and Z obtained from two repetitions of target measurements (6 per $\log$ ) for nine poplar trees considered individually $(\mathbf{A})$ and with respect to the position of the $\log$ in the tree $(\mathbf{B})(1=$ butt $\log , 10=$ highest $\log$, length of $\log \sim 2 \mathrm{~m}$ ).
Table II. Interval of uncertainty assessed for each of the 3D axes using two repetitions of the target measurements without moving the tacheometer for nine poplar trees with respect to the position of the targets on the stem.

\begin{tabular}{lll}
\hline & Logs 1-6 & Logs >6 \\
\hline Horizontal axis X (diameter) & $\pm 5.4 \mathrm{~mm}$ & $\pm 15.1 \mathrm{~mm}$ \\
Horizontal axis Y (distance to tree) & $\pm 7.2 \mathrm{~mm}$ & $\pm 20.8 \mathrm{~mm}$ \\
Vertical axis Z (height) & $\pm 3.5 \mathrm{~mm}$ & $\pm 7.3 \mathrm{~mm}$ \\
\hline
\end{tabular}

both with total station and the AMEB. In that case, the measurements with AMEB are considered as a reference which is justified by its higher accuracy.

Even if the range of distances compared is limited by the length of the $\log$, this approach to the accuracy is interesting since the accuracy is assessed from confident measurements. Such distances are close to those which could be used in a non destructive assessment of the quality of standing trees to calculate curvature, for example.

This analysis was performed using the data measured on poplar FV1 in order to test our method. Three classes of distance were represented and were approximately centred on $125 \mathrm{~mm}, 700 \mathrm{~mm}$ and $1750 \mathrm{~mm}$ resulting from the arrangement of targets along the tree. The maximum absolute error was $6.2 \mathrm{~mm}$ for the 150 distances compared, the mean value was $1.6 \mathrm{~mm}$ with a standard deviation of $1.3 \mathrm{~mm}$. The maxi- mal relative error was $5 \%$, and on average $0.7 \%$. This error could be partially reduced by optimising the choice of the three targets per log used for tree reconstruction.

\subsection{Applied example}

As an applied example, some preliminary results on the relationships between shape and tension wood location are derived from the measurements of the FV1 poplar (see Tab. I).

After the completion of the initial stages of the procedure presented above (target positioning and measurement, log cutting, measurement of log shape and target location with AMEB), the internal structure of this tree was described using 41 discs taken at each $50 \mathrm{~cm}$ along the first 20 metres of the trunk. The ring shape and the tension wood pattern were measured on each discs according to the method described in Section 2.4.3.

Using these geometric data, we computed the pith location, the centre of gravity of the disc [13] and the centre of gravity of the tension wood area. The location of each disc inside the tree being known, it was possible to estimate the local stem slope as the angle between the vertical axis and a line joining the centre of gravity of one disc to the next one. Figures 6 and 7 show that this local slope explained a large part of the variation along the tree of the disc eccentricity (distance from the disc centre of gravity to the pith, $\mathrm{R}^{2}=0.57$ ) and of the tension 


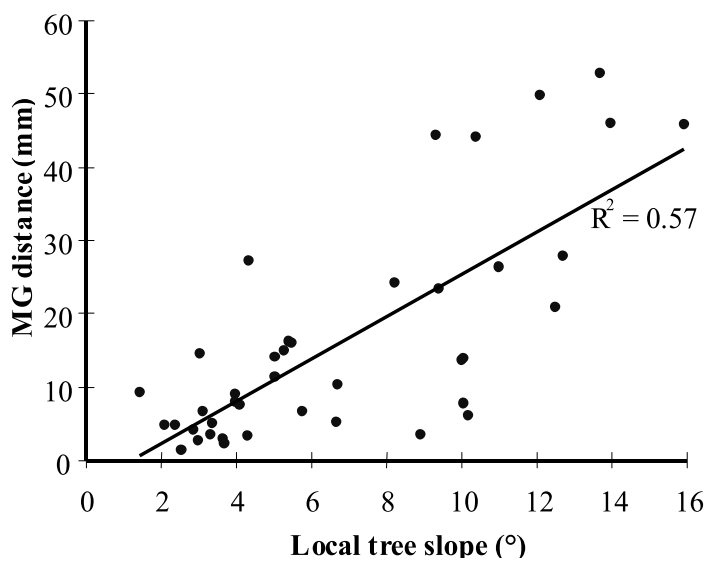

Figure 6. Local tree slope vs. distance from the pith to the disc centre of gravity (distance MG shown in Fig. 4).

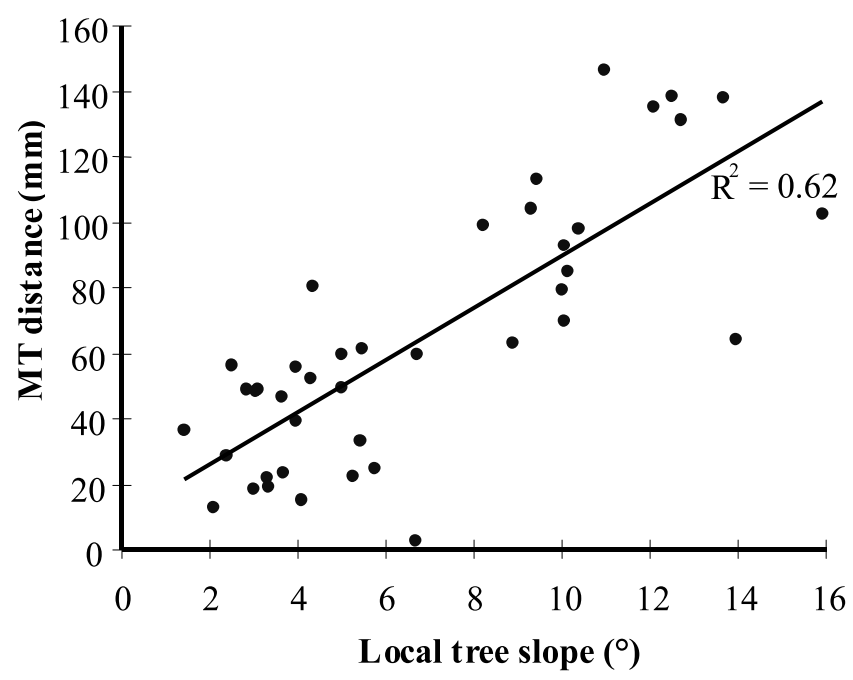

Figure 7. Local tree slope vs. distance from the pith to the tension wood centre of gravity (distance MT shown in Fig. 4).

wood eccentricity (distance from the centre of gravity of the tension wood areas to the pith, $\mathrm{R}^{2}=0.62$ ). In Figure 8, it can be observed that the largest proportion of tension wood was located on the opposite side of the direction in which the tree was leaning. Both the orientations of the local stem slope and the tension wood centre of gravity relative to pith followed a similar pattern along the bottom meters of the trunk $\left(R^{2}=0.63\right.$ for the first 26 discs), which became asynchronous above $12 \mathrm{~m}$ tree height $\left(R^{2}=0.17\right.$ for the full set of data). This is probably due to the increasing effect of the crown eccentricity.

These simple results obtained from only one tree already show a potential of the method described for further studies devoted to linking tree shape and wood quality.

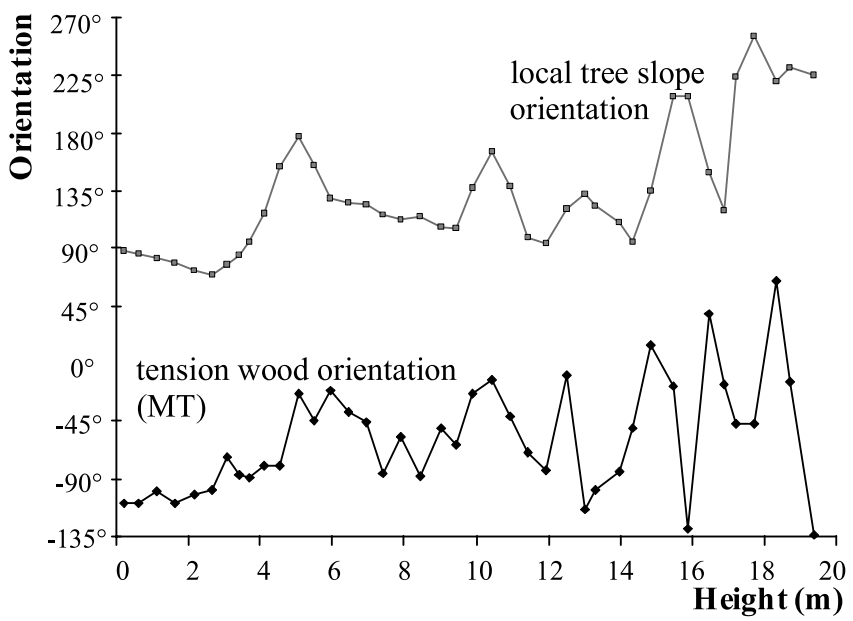

Figure 8. Variation of the local stem slope orientation (azimuth) and of the tension wood centre of gravity orientation relative to pith (angle between the horizontal axis and the line MT shown in Fig. 4) with stem height.

\section{CONCLUSIONS AND PERSPECTIVES}

The experimental method which is described in this article, aims to improve studies on the relationship between the mature tree shape and the inner wood quality. The advantage of this method is the close link between detailed geometrical information and wood properties or internal characteristics such as ring shape or reaction wood occurrence which allows a better understanding of the complex and subtle relationship between internal and external appearance of the tree.

This method remains time consuming and destructive but fulfils one of its objectives i.e. to identify and quantify relevant information linking the 3D shape of annual rings and wood properties such as reaction wood. Some outputs could be criteria which will be useful for foresters to improve their assessment of the quality of standing trees, or in the sawmilling industry for grading logs by deriving some criteria from the log shape measurements which are already common practice. Furthermore, this method might become a reference method in tree shape measurement provided that wood quality is involved. On-going research aims to model the location of poplar tension wood inside the tree based on data collected from the additional 9 trees (see Tab. I).

Different variants of the method will be tested and the methodology will be evaluated, improved and simplified with respect to an easy and time efficient use.

Acknowledgements: The authors are in particular grateful to M. Broto and F. Rodriguez (Universitat de Lleida) for their help during the field campaign and to C. Houssement and E. Farre (Lerfob INRAENGREF) for their assistance in laboratory work. This research was partly funded by CICYT (Comisión Interministerial de Ciencia y Tecnología, Spain) project AGL2000-1255. 


\section{ANNEX 1}

Estimation of the geometrical transformation corresponding to the change between local and global coordinate systems from three non aligned points measured in both systems.

Considering a rigid body where a triplet of non-aligned points $\left(P_{0}, P_{1}, P_{2}\right)$ is marked, the positions of these points are measured twice in two different Cartesian coordinate systems. We consider $(O, \vec{X}, \vec{Y}, \vec{Z})$ as the global system and $\left(O^{\prime}, \vec{x}, \vec{y}, \vec{z}\right)$ as the local system where the geometry of the body is measured in detail.

From the triplet, a new orthonormal coordinate system is built, $\left(P_{0}, \vec{u}, \vec{v}, \vec{w}\right)$ where is defined as follows:

$$
\begin{gathered}
\vec{u}=\frac{\overrightarrow{P_{0} P_{1}}}{\left\|P_{0} P_{1}\right\|}, \\
\vec{v}=\frac{\vec{u} \otimes \overrightarrow{P_{0} P_{2}}}{\| \overrightarrow{P_{0} P_{2} \|}}, \\
\vec{w}=\vec{u} \otimes \vec{v},
\end{gathered}
$$

where $\otimes$ is the cross product of two vectors and $\|\vec{u}\|$ is the length of vector $\vec{u}$.

By considering these vectors in each coordinate system, the rotation matrix A can be defined from the three following vectorial equations:

$$
\begin{aligned}
& \vec{u}^{g}=A \vec{u}^{l}, \\
& \vec{v}^{g}=A \vec{v}^{l}, \\
& \vec{w}^{g}=A \vec{w}^{l} .
\end{aligned}
$$

These equations can be translated into a set of nine solved algebric equations. By associating this rotation to the translation defined by the vector $\overrightarrow{O P_{0}}$ expressed in the global coordinate system, all coordinates of the measured points in the local coordinate system can be obtained in the global coordinate system.

\section{ANNEX 2}

Technical specifications of the main components of the measurement chain.

Tacheometer: Field measurement of the targets.

Model LEICA TCR307 reflectorless.

Angle Measurement 5".

Maximal distance measurement $80 \mathrm{~m}$.

Accuracy $3 \mathrm{~mm}$ at $80 \mathrm{~m}$.

Measurement time $3 \mathrm{~s}$.

Magnification $\times 30$.

AMEB: Laboratory measurements of the targets and of the external shape of the logs.
Angular Coder: HEINDENHAIN, ROD 450.

Minimal angular step $1 / 100^{\circ}$

Laser: $\quad$ LIMAB LMS6035S

Accuracy $0.5 \mathrm{~mm}$ at $600 \mathrm{~mm}$

1axis robot: CHARLY ROBOT PE225

Length $2.25 \mathrm{~m}$

Step by Step Motor $140 \mathrm{Ncm}$

Minimal step $12.5 \mu \mathrm{m}$

Accuracy $0.1 \mathrm{~mm}$ at $2 \mathrm{~m}$.

\section{REFERENCES}

[1] Alteyrac J., Fourcaud T., Castera P., Stokes A., Analysis and simulation of stem righting movements in Maritime pine (Pinus pinaster Ait.), in Proc. 3rd Workshop IUFRO WP S5.01-04, La Londe-Les-Maures, France, 1999, 644 p.

[2] Archer R.R., Growth stresses and strains in trees, Timell T.E. (Ed.), Springer-Verlag Series in Wood Science, $240 \mathrm{p}$.

[3] Clarke H., The distribution, structure, and properties of Tension Wood in beech (Fagus sylvatica L.), J. For. (1937) 85-93.

[4] Danjon F., Sinoquet H., Godin C., Colin F., Drexhage M., Characterisation of structural tree root architecture using $3 \mathrm{D}$ digitising and AMAPmod software, Plant Soil 211 (1999) 241-258.

[5] Fourcaud Th., Lac P., Mechanical analysis of the form and internal stresses of a growing tree by the Finite Element Method. Proc. Engineering Systems Design and Analysis, ASME, Montpellier, France, July 1-4, 1996, 77, pp. 213-220.

[6] Fournier M., Chanson B., Guitard D., Thibaut B., Mécanique de l'arbre sur pied: modélisation d'une structure en croissance soumise à des chargements permanents et évolutifs. 1. Analyse des contraintes de support. 2. Analyse tridimensionnelle des contraintes de maturation, cas du feuillu standard, Ann. Sci. For. 48 (1991) 513-546.

[7] Fournier M., Chanson B., Thibaut B., Guitard D., Mesures des déformations résiduelles de croissance à la surface des arbres, en relation avec leur morphologie. Observations sur différentes espèces, Ann. Sci. For. 51 (1994) 249-266.

[8] Godin C., Representing and encoding plant architecture: A review, Ann. For. Sci. 57 (2000) 413-438.

[9] Jourez B., Le bois de tension. 1. Définition et distribution dans l'arbre. Biotechnologie, Agronomie, Société et Environnement 1 (1997) 100-112.

[10] Mattheck C., Kubler H., Wood. The internal optimization of trees, Springer-Verlag, Berlin Heidelberg, 1995, 128 p.

[11] Radi M., Castera P., Qualification de deux pins maritimes en liaison avec la structure de leur bois, Ann. Sci. For. 49 (1992) 185-200.

[12] Sacre E., Caractéristiques anatomiques et physiques du bois des peupliers 'I 214', 'robusta' et 'gelrica' aux stades précoce et adulte, Bulletin de la Société Royale Forestière de Belgique 84 (1977) 321-338

[13] Saint-Andre L., Leban J.-M., An elliptical model for tree ring shape in transverse section. Methodology and case study on Norway Spruce, Holz Roh-Werkst 58 (2000) 368-374.

[14] Sinoquet H., Rivet P., Measurement and visualization of the architecture of an adult tree based on a three-dimensional digitising device, Trees 11 (1997) 265-270.

[15] Thomas R., Analyse des formes de troncs par photogrammétrie pour caractériser la qualité des bois. Application au pin sylvestre de Lozère. Ph.D. thesis in Wood Science, ENGREF Montpellier, France, mars 2000, 193 p.

[16] Timell T.E., Compression wood in gymnosperms, Springer-Verlag, Berlin Heidelberg, 1986, 2150 p. 